\title{
CBCT Diagnosis to the Athletic People Suffering TMJ Pain and/or Dysfunction before a Prolong Therapy with Platelet Rich Plasma
}

\author{
Shefaa Hussain ${ }^{1}$, Abdul Razzaq Jabr AL.Majidi ${ }^{2}$, Zainab H.AL-Ghurabi ${ }^{3}$, Samirajameel Al-Obaidi ${ }^{4}$ \\ ${ }^{1}$ College of Dentistry, AL Esraa University, Baghdad-Iraq \\ ${ }^{2}$ Dean of the Faculty of AL Esraa University, Baghdad-Iraq \\ ${ }^{3}$ College of Dentistry, University of Baghdad, Baghdad-Iraq \\ ${ }^{4}$ Department Conservative Dentistry, University of Theqar
}

\begin{abstract}
Aim of study: This study designed to clear the role of CBCT in diagnosis of TMJ in athletes who have TMD or pain prior to treating with PRP. Methods: 30 patients with an age range between 18 and 25years. Volunteers with limited mouth opening, joint sound, and pain from different Baghdad university students with sports hopes patient were sent to be evaluated radiographicly with CBCT in Al ESraa university; Result: The improvements obtained with the PRP injection in group I were maintained during the fallow -up period.At the end of the fallow -up period provide $45 \%$ improvements, group II $40 \%$ improvements Group III $15 \%$ improvements. Conclusion: $C B C T$ is relatively recent device with low radiation dose and high accuracy in bony evaluation of TMJ problem and PRP found was curative in preventing recurrent TMJ dislocation and relief pain .
\end{abstract}

Keywords: Athletic people, CBCT, Platelet rich plasma

\section{Introduction}

Complex etiologic factors like trauma, emotional stress, orthopedic instability, muscular hyperactivity, inflammatory and degenerative diseases, which compromise the equilibrium of the temporomandibular joint (TMJ), have been implicated in the development of temporomandibular joint disorders (TMD), cause of this disorder is not good understood [1,2].

In athletes person, many of sports activates may be come in contact with (TMJ) which lead to trauma andlor clenching in TMJ result in pain andlor dysfunction with TMJ, like Basketball, Soccer or football, Boxing, Martial arts, Hockey[3]

Usually TMJ diagnosed clinically but sometimes radiological investigations are importance in the diagnostic assessment of a patient with TMD.the rationale imaging selection for diagnosis, treatment planning and follow up of a patient with conditions affecting the TMJ Conventional radiographic TMJ projections like transpharyngeal, transcranial, panoramic radiograph, conventional tomographic sections of TMJ may be adequate in a number of clinical situations, but there are bony alterations that occur in these disorders like erosions, osteophytes, pneumatisation of articular eminence that are difficult to be detected in conventional radiographs due to overlapping of the anatomic structures[4,5].

Recently most of TMJ proplems treated with plat late rich plasma (PRP) which derived from the patient's blood to encourage tissue function by rebuilding and enhancing its metabolism sets itself apart specially if there is any bony changes, there for this type of treatment accurateinformation should be obtained about bony area in TMJ and in this case patients should have been sent to CBCT diagnosis $[6,7,8,9,10,11]$

Nowadays, CBCT appeared to change the view and diagnosis way of the oral and maxillofacial surgeons by providing an accurate evaluation and treatment planning prior to any operation, three dimentional (3D) cone beam computed tomography (CBCT) introduce high benefits in maxillofacial region since it supply the surgeon or dentist with high resolution and multiple projections with very thin slice 'but it have one important limitation which is high dose of radiation $[12,13]$.

This study designed to clear the role of CBCT in diagnosis of TMJ in athletes who have TMD or pain prior to treating with PRP.

\section{Materials and Method}

\section{Patients}

In this retrospective study the data was obtained from volunteers of athletes student from university of Baghdad referred to Al ESraa universitylcollage of dentistry for (30) patients with age ranged from 18-25 years old, all of them come to CBCT as a voluntary for TMJ diagnosis.

The cases which diagnosed withCBCT were difficult mouth opening, joint sound and pain. This study begin at February 2016 to December 2017. This study have been approved by Al ESraaCollege of Dentistry, every patient informed about research and they sign for this. 


\section{International Journal of Science and Research (IJSR) \\ ISSN (Online): 2319-7064}

Index Copernicus Value (2015): 78.96 | Impact Factor (2015): 6.391

\section{Imaging:}

The scanning was done with (Romexisplanmega 3D CBCT) tube voltage $\mathrm{kV} 90$, tube current with $\mathrm{mA} 6.3$ and exposure time was $27 \mathrm{~s}$., the field of view was measured with $5 \mathrm{~cm} \times 3.7 \mathrm{~cm}$ with $0.400 \mathrm{~mm}$ slice thickness.

TMJ were scanned or diagnosed with three multiplanar views, coronal, sagitta, and axial, in addition to reconstructed panoramic view and three dimentional image.

The CBCT radiograph (multiplaner views) of the TMJ were viewed for the presence or abscence any abnormalities of the bony component of TMJ, bilateral sides of the mandible radiographs (CBCT) were evaluated to determine presence, abscence any deffect.

There are many applications of this device for TMG diagnosis which include

- TMD ddiagnosis

- Mandibular movement analysis

- Condyle-fossa relation during jaw movement

- Preoprative planning

- Postoprativetreatment verification

\section{Image evaluation}

All radiographs were evaluated to ensure the diagnosis obtained by agreement between oral maxillofacial radiologist and oral maxillofacial surgeon for consensus agreement.

Exclusive factor

- Injuries to the jaw area

- Various forms of arthritis

- Dental procedures

- Genetics

- Hormones

- Low-level infection

- Auto-immune diseases

- Stretching of the jaw as occurs with inserting a breathing tube before surgery

- Clenching or grinding of the teeth

\section{Results}

In this study 30 volunteers were diagnosed with CBCT, they classified to three groups according their complain as shown in table 1, after diagnosis with CBCT, the diseases were classify into 4groups 1- osteolyte and osteophyte, as shown in fig 4, 2-condylar dislocation as shown in figer 2,3, 3- anterior or posterior disc displacement and 4- pain, the treatment plan with PRP was determined, the gold standard for accuracy of CBCT diagnosis was the progression of patients complain

Table1: Distribution the number of patient according to the type of pain

\begin{tabular}{|c|c|c|}
\hline Volunteer patient complains & No.of patient & $\%$ \\
\hline $\begin{array}{c}\text { Pain , Joint Sound- Limitation in mouth } \\
\text { opening }\end{array}$ & 13 & $43.3 \%$ \\
\hline Pain , Joint sound & 5 & $16.6 \%$ \\
\hline Pain & 12 & $40 \%$ \\
\hline
\end{tabular}

Table 2: Distribution of TMJ pain according to the $\mathrm{X}$ - ray finding

\begin{tabular}{|c|c|c|}
\hline Radio graphic finding of TMJ & $\begin{array}{c}\text { No. of } \\
\text { patient }\end{array}$ & $\%$ \\
\hline $\begin{array}{c}\text { TMJ with osteoarthritis ( osteolyte and } \\
\text { osteophyte) }\end{array}$ & 5 & $16.6 \%$ \\
\hline $\begin{array}{c}\text { TMJ with dick displacement (anteriorly or } \\
\text { posteriorly) }\end{array}$ & 3 & $10 \%$ \\
\hline Condylar dislocation & 10 & $33.3 \%$ \\
\hline $\begin{array}{c}\text { TMJ pain with Myofacial pain disorder ( } \\
\text { MFPD) }\end{array}$ & 12 & $40 \%$ \\
\hline
\end{tabular}

Table 3:Distribution of patients according to the number of injection and improvement

\begin{tabular}{|c|c|c|c|c|}
\hline Duration time & No.of injection & improved & No of patient & $\%$ \\
\hline 3-6 month & 3 & 9 & 10 & 45 \\
\hline 3 month only & 3 & 8 & 15 & 40 \\
\hline One month & 1 & 3 & 5 & 15 \\
\hline
\end{tabular}

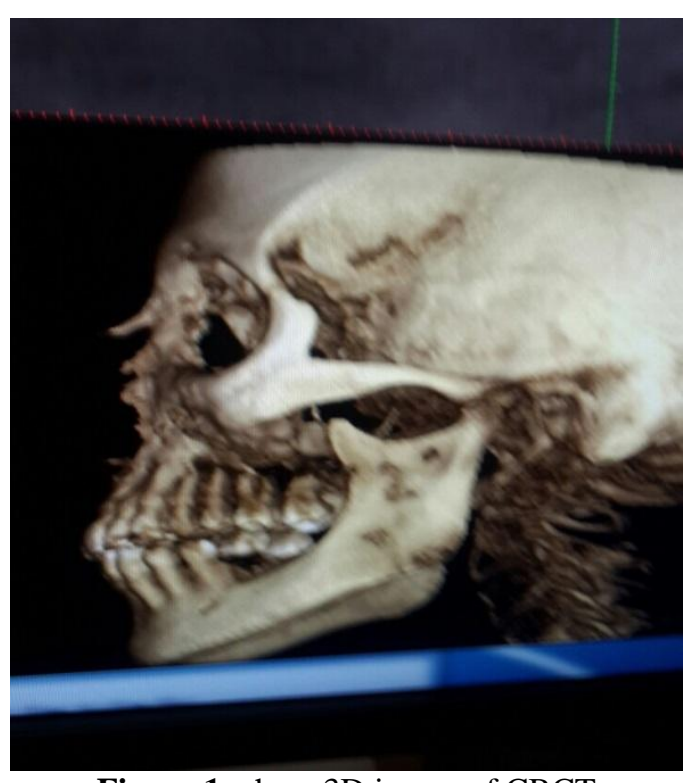

Figure 1: show 3D image of CBCT

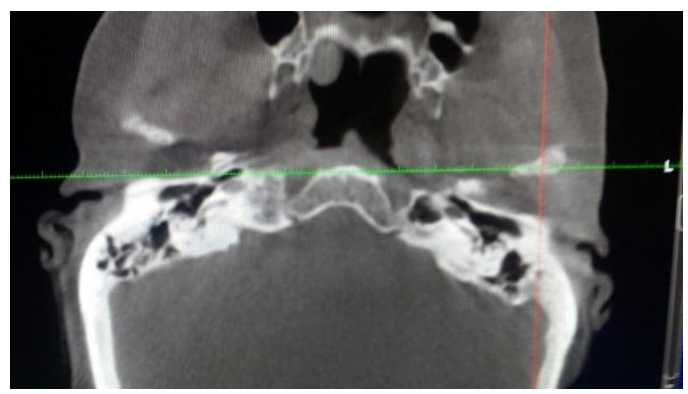

Figure 2: show dislocation of the condyle 


\section{International Journal of Science and Research (IJSR) \\ ISSN (Online): 2319-7064}

Index Copernicus Value (2015): 78.96 | Impact Factor (2015): 6.391

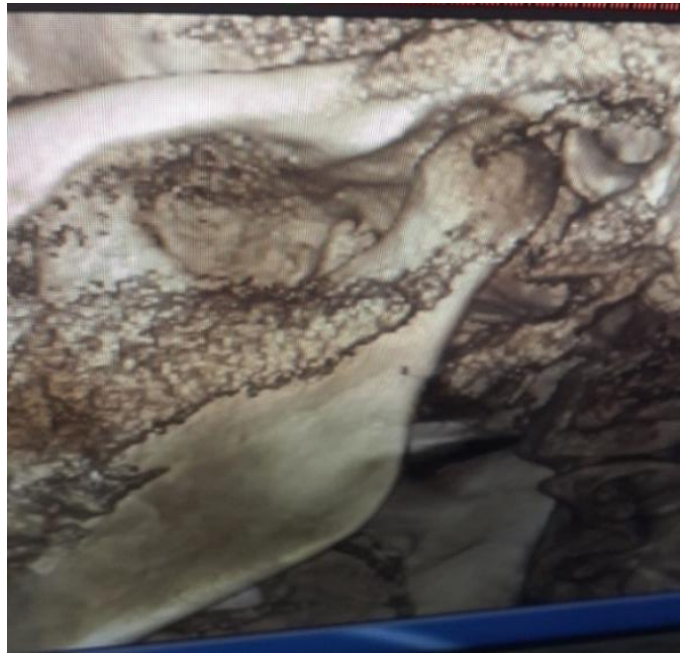

Figure 3: 3D image show condylar dislocation

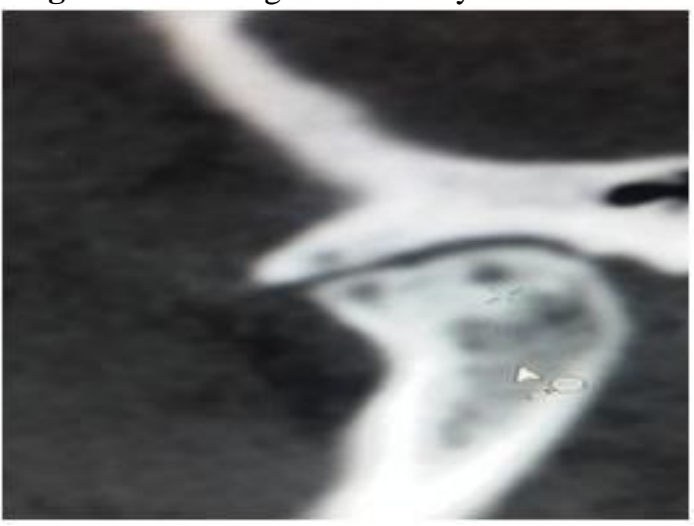

Figure 4: ostiolytic changes in TMJ

\section{Discussion}

TMJ one of the most important structures in oral and maxillofacial region, because it expose to load and pressure from different life style.

Sports like tennis, box ....are one of the causes of this load, for this reason our study designed to diagnosis TMJ of athletic people with CBCT before treating with PRP.

In our study there are three important causes for TMJ problem which include pain in 12 patients, pain, joint sounds and limitation in mouth opening in 13 patients and pain with joint sound in5 patients, as shown in table1, and this result come in agreement with [13].

Regarding to the radiographic finding it was found TMJ with osteoarthritis (osteolyte and osteophyte) in 5 patients, TMJ with disc displacement in 3 patients, condylar dislocation in 10 patients and TMJ pain with myofacial pain disorder in 12 patients. And this indicat for a highyaccuresy of CBCT this result confirmed with[14,15,16]

The improvement of TMJ after injection of PRP was as fallow from 3-6 month with 3 injectionsprognosis was seen in 9 from 10 patient, 3 month with 3 injections prognosis was seen in 8 from 15 patients, and 1 month with 3 injection prognosis was seen in 1 from 3 month, so in this study the improvement or prognosis of RPR was clear in most of TMJ problem, this result com in agreement with [17] who stated that, Injection with platelets rich plasma was significantlymore effective in improvements of the extent of maximalmouth opening, statistics result demonstrated a significantreduction in the VAS values of pain at rest, motion and masticationcompared to the baseline VAS values.

\section{References}

[1] Okesonjp. 4thed.st.Louis (MO):Mosby;1998.Managmemt of tempromandibular disorder and occlusion.

[2] Marques AP,Perrella.A, AritaES.Assessment of simulated mandibular condyle lesions by cone beam computed tomography2010;467-74.

[3] Franchini M, Dupplicato P, Ferro I, De Gironcoli M, Akiegheri L. Efficacy of platelet gel in reconstructive bone surgery. Orthopedics. 2005 Feb;28(2):1 61-3

[4] MelogoO,YilmazAB,Akgul HM. Pneumatization of the articular eminence on cone beam computed .Dentomaxillofac Radiol.2011[PMCfreearticle].

[5] ScarfeWC,farmanAG,SukovicP.Clinical application of cone :Beam computed tomography in dental practice 2006;75-80.

[6] Anitua E, Andia I, Ardanza B, Nurden P, Nurden AT. Autologous platelets as a source of proteins for healing and tissue regeneration ThrombHaemosL 2004 Jan;91:4-15

[7] Doral MN, Alam M, Bozkurt M, Turhan E, Atay OA, Donmez G, Maffolli N. Functional anatomy of the Achilles tendon. Knee Surg Sports TraumatolArthrosc. 2010 May; 18(5):638-643

[8] Filardo G, Presti ML, Kon E, Marcacci M. Nonoperative biological traetment approach for partial Achilles tendon lesion. Orthopedics. 2010 Feb;33(2):1 20-3.

[9] Hall MP, Band PA, Meislin RJ, Jazrawi LM, Cardone DA. Platelet-rich plasma: current concepts and application in sports medicine. J Am AcadOrthop Surg. 2009 Oct;17(10):602

[10] Lanv M. Wolford. DM0 ${ }^{\text {s11 }}$ From the Department of Oral and Maxillofacial Surgery, Baylor College of Dentistry, Texas A\&M University System, Dallas, Texas; and the Department of Oral and Maxillofacial Surgery, Baylor University Medical Center, Dallas, Texas.2001.

[11] Chang TH, Yuh DY, Wu YT, Cheng WC, Lin FG, Shieh YS, Fu E, Huang RY. The association between temporomandibular disorders and joint hypermobility syndrome: a nationwide population-based study. Clin Oral Investig. 2015 Feb 17. [Epub ahead of print]

[12] MircaleAC,MukherjiSK.CTofthehead and neck, part 2: Clinical applications .Amj2009;92[PubMed].

[13] Gupta R,GrasruckM,SuessC,Flat -panel volume CT: Fundamental principles, and system characterization Eur Radiol..2006.

[14] Gaia BF, Sales MAO, Perrella A, Fenyo-Pereira M, Cavalcanti MGP. Comparison between cone-beam and multislice computed tomography for identification of simulated bone lesions. Braz Oral Res 2011; 25: 3628.

[15] Schulze D, Heiland M, Thurmann H, Adam G. Radiation exposure during midfacial imaging using 4and 16-slice computed tomography, cone beam

\section{Volume 6 Issue 7, July 2017 www.ijsr.net}




\section{International Journal of Science and Research (IJSR) \\ ISSN (Online): 2319-7064}

Index Copernicus Value (2015): 78.96 | Impact Factor (2015): 6.391

computed tomography systems and conventional radiography. DentomaxillofacRadiol 2004; 33(2): 836.

[16] Kobayashi K, Shimoda S, Nakagawa Y, Yamamoto A. Accuracy in measurement of distance using limited cone-beam computerized tomography. Int $\mathrm{J}$ Oral Maxillofac Implants 2004; 19(2): 228-31

[17] Ra'ed M. Ayoub Al-Delayme1,2,8 • Shefaa H. Alnuamy • FirasTaha Hamid5 Tariq Jassim Azzamily6 - Salah AbdulMahdy Ismaeel2 - R. Sammir4 M. Hadeel4 • Jafaar Nabeel4 • R. Shwan4 • Shahad Jamal Alfalahi4 Alaa Yasin7. The Efficacy of Platelets Rich Plasma Injection in the Superior Joint Space of the Tempromandibular Joint Guided by Ultra Sound in Patients with Non-reducing Disk Displacement. J. Maxillofac. Oral Surg. DOI 10.1007/s12663-016-09119

Volume 6 Issue 7, July 2017 www.ijsr.net 